\title{
Characteristics and development of European cyclones with tropical origin in reanalysis data
}

\author{
Mark M. Dekker ${ }^{1,2}$ - Reindert J. Haarsma ${ }^{1} \cdot$ Hylke de Vries $^{1} \cdot$ Michiel Baatsen $^{2} \cdot$ \\ Aarnout J. van Delden ${ }^{2}$
}

Received: 4 March 2016 / Accepted: 3 March 2017 / Published online: 24 March 2017

(c) The Author(s) 2017. This article is an open access publication

\begin{abstract}
Major storm systems over Europe frequently have a tropical origin. This paper analyses the characteristics and dynamics of such cyclones in the observational record, using MERRA reanalysis data for the period 19792013. By stratifying the cyclones along three key phases of their development (tropical phase, extratropical transition and final re-intensification), we identify four radically different life cycles: the tropical cyclone and extratropical cyclone life cycles, the classic extratropical transition and the warm seclusion life cycle. More than $50 \%$ of the storms reaching Europe from low latitudes follow the warm seclusion life cycle. It also contains the strongest cyclones. They are characterized by a warm core and a frontal T-bone structure, with a northwestward warm conveyor belt and the effects of dry intrusion. Rapid deepening occurs in the latest phase, around their arrival in Europe. Both baroclinic instability and release of latent heat contribute to the strong intensification. The pressure minimum occurs often a day after entering Europe, which enhances the potential threat of warm seclusion storms for Europe. The impact of a future warmer climate on the development of these storms is discussed.
\end{abstract}

Keywords Cyclones $\cdot$ North Atlantic $\cdot$ Extratropical transition $\cdot$ Reanalysis

Mark M. Dekker

m.m.dekker@outlook.com

1 Royal Netherlands Meteorological Institute (KNMI), De Bilt, Netherlands

2 Institute for Marine and Atmospheric Research Utrecht, University of Utrecht, Utrecht, Netherlands

\section{Introduction}

Hurricane-force ( $>$ Beaufort $12,>32.6 \mathrm{~m} / \mathrm{s}$ ) winds pose a significant threat to coastal regions, inflicting severe damage to infrastructure and agriculture (Dorland et al. 1999). In the North Atlantic, most hurricanes originate and stay near the Caribbean sea, the Gulf of Mexico or along the eastern coast of the United States. Upon entering the midlatitudes, they transform into extratropical storms. Only a small subset of these storms still have hurricane-force winds when they reach Europe. The question of whether this will change in the future has been debated. Recent research suggests that climate warming causes a poleward and eastward extension of the hurricane genesis area (Zhao and Held 2012; Murakami et al. 2012). However it is unclear whether these changes and the increase in sea surface temperatures (SSTs) are large enough to increase significantly the number of hurricane-force storms of tropical origin that will reach Europe. Recent studies have shed some light on this debate. Using a high resolution ( 25 $\mathrm{km}$ grid size) global climate model, Haarsma et al. (2013) showed that the frequency of hurricane-force storms are projected to increase considerably in Europe by the end of the twenty-first century. They suggested that higher SSTs and extension of the hurricane breeding ground imply that tropical cyclones under these future conditions are likely to have experienced less dissipation in their northward propagation when reaching the midlatitudes, thereby facilitating reintensification through merging with a baroclinic wave. Baatsen et al. (2015) subsequently showed for these model simulations that a high percentage of future cyclones that enter Europe reattain a lower warm core and that a pronounced part of these so-called warm seclusions upholds a sting jet. A sting jet is a mesoscale feature that causes exceptionally strong winds close to the surface (Browning 
2004). It develops at the end of the back bent front to the south-east of the warm core and is associated with downward motion. As these cyclones pose a threat to Europe, it is crucial to assess whether observation-based analysis of the development of the cyclone structure lends further support to the key result of Baatsen et al. (2015), specifically that warm seclusion cyclones typically produce the strongest winds. This will be investigated here.

Concerning structural development, extratropical transition is a major feature in cyclones from low-latitudes that reach Europe. Of the North-Atlantic tropical cyclones, about half undergoes extratropical transition (Hart and Evans 2001), which includes changes to the structure of the cyclone, such as asymmetries in wind, thermal structure and moisture field (Klein et al. 2000). This transition is the consequence of the interaction of the northward propagating tropical cyclone with the mid latitude environment, which may include the presence nearby troughs, increased baroclinicity, vertical shear, cooler SSTs and strong SST gradients (Jones et al. 2003; Hart and Evans 2001; Hart et al. 2006).

Analyses of cyclone life cycles have been done in various ways. For example, Agusti-Panareda et al. (2004) described three different stages in their study of hurricane Irene (1999): the tropical stage, the transformation stage and the extratropical stage [complementary to the two stages used in Klein et al. (2000)]. This has the potential of describing different parts of a particular cyclone evolution, but does not qualitatively distinguish one cyclone life cycle from another. Hart (2003) proposed a three-dimensional cyclone phase space using relative thickness symmetry, which is an approximate measure of frontal nature of the cyclone and the vertical derivative of the horizontal height gradient (in two different atmospheric layers), which is a measure of the cyclone thermal wind and thus the thermal nature of the core. Using this phase space analysis, Hart showed the potential to distinguish different cyclone life cycles and therefore to categorize these life cycles. Hart (2003) used NCEP-NCAR reanalyses to examine a large number of storms and subsequently described different kinds of life cycles using cyclone examples. Hart et al. (2006) used this life cycle analysis to investigate the dynamics of the posttransition evolution. This paper further extends the research on cyclone life cycles, by focusing on storms that enter Europe. An important question is whether a connection exists between the cyclone life cycle and cyclone strength, and if so, what physical processes are behind this connection.

In this paper the MERRA reanalysis for the period 1979-2013 is used (details of this data set will be given in Sect. 2). This data set, together with the analysis tools, is described in the methodology section. To distinguish and classify the different life cycles of those cyclones that enter
Europe, the phase space analysis of Hart (2003) is used. This is discussed in the methodology (Sect. 2), together with the cyclone tracking and the indices for baroclinic instability. Section 3 contains the actual classification based on the mentioned phase space analysis. In Sect. 4 the structural evolution of the different life cycles is described. Section 5 contains the conclusions and a discussion with respect to the impact of global warming.

\section{Methodology}

\subsection{Model specifications}

For this study the MERRA reanalysis of the Global Modeling and Assimilation Office (GMAO) has been used, which is conducted with version 5.2.0 of the GEOS-5 ADAS. The resolution of the MERRA data set is $0.66^{\circ}$ in longitude and $0.5^{\circ}$ in latitude and it has 72 vertical layers. For the analysis the vertical resolution has been interpolated to an equidistant resolution of 17 layers of $50 \mathrm{hPa}$ from 1000 to $200 \mathrm{hPa}$, similar to that used in Hart (2003). The main arguments for choosing the MERRA data set are its relatively high horizontal resolution compared to other reanalyses, and the availability of a few fields, such as mean sea level pressure and $850 \mathrm{hPa}$ temperature on an hourly interval (other reanalyses usually have 3-hourly or 6-hourly intervals). High spatial and temporal resolution are important for a reliable analysis and tracking of the cyclones. We realize that reanalysis data is still model dependent and that the horizontal resolution is much coarser than the observation database by design.

Schenkel and Hart (2012) have compared the representation of tropical cyclones in five different reanalysis data sets. In the North Atlantic, which is our focus area, the quality of the ERA-Interim, ERA-40 and MERRA reanalysis data sets appeared to be comparable due to the dense observations. The two reanalysis data sets that are significantly better in terms of tracks and intensity, the Climate Forecast System Reanalysis (CFSR) and the Japanese 25-year Reanalysis (JRA-25) use vortex relocation that can result in a nonphysical life cycle and are therefore not useful for our analysis.

\subsection{Cyclone detection and tracking}

The analysis period is 1979-2013 for the months of August through November, which is shifted by one month with respect to the main hurricane season (July-October). This is motivated by the enhanced baroclinic instability later in the season, which is important for extratropical transition. The same months were also analyzed by Baatsen et al. (2015). Cyclone tracking is done for the region $100^{\circ} \mathrm{W}-40^{\circ}$ 
$\mathrm{E}$ and $0^{\circ} \mathrm{N}-90^{\circ} \mathrm{N}$. Around local $10 \mathrm{~m}$ wind maxima (found using the threshold of $\geq 14 \mathrm{~m} \mathrm{~s}^{-1}$ ), the lowest sea level pressure within a $10^{\circ}$ range is defined as a cyclone center. The threshold of $\geq 14 \mathrm{~m} \mathrm{~s}^{-1}$ is intentionally chosen relatively low to prevent gaps in the tracking of cyclone. The $10^{\circ}$ range around the wind maximum prevents a single storm's location to be counted twice.

Tracking is done using hourly data and for the analysis, 6-hourly data is used. To track cyclones, the detection described above is done at each timestep and the found pressure minimum is automatically linked to a past pressure minimum if it is within $10^{\circ}$ range of a pressure minimum one timestep later. A newly found pressure minimum is linked to a past pressure minimum up to $16 \mathrm{~h}$ back. This period is optimal for the tracking routine, although the results were not very sensitive between 12 and $20 \mathrm{~h}$. In some cases, manual corrections are required, for example if two systems merge or if a cyclone starts following the track of a nearby other storm. These corrections are based on horizontal $850 \mathrm{hPa}$ equivalent potential temperature $\left(\theta_{E}\right)$ and sea level pressure $(p)$ fields. After the tracking of the cyclones the following selection criteria are used:

- At least once throughout the cyclone life cycle, the cyclone attains a wind speed of at least Beaufort class 8 $\left(>17.2 \mathrm{~m} \mathrm{~s}^{-1}\right)$.

- The cyclone is tracked over a period of at least 3 days.

- The cyclone originates from latitudes equatorward of $37.5^{\circ} \mathrm{N}$. This criterion selects cyclones of tropical origin. The specific value of $37.5^{\circ} \mathrm{N}$ is based on the premise that extratropical transition occurs at $30^{\circ} \mathrm{N}-35^{\circ} \mathrm{N}$ during early and late hurricane season and at $40^{\circ} \mathrm{N}-50^{\circ}$ $\mathrm{N}$ during peak of hurricane season (Hart and Evans, 2001).

- The cyclone reaches Europe, which is defined as $15^{\circ}$ $\mathrm{W}-40^{\circ} \mathrm{E}$ by $37.5^{\circ} \mathrm{N}-90^{\circ} \mathrm{N}$ (indicated in Fig. 4).

This tracking system is based on the algorithm used in Baatsen et al. (2015). The results were extensively and manually checked to guarantee similar quality as well known advanced tracking systems such as Hodges (1994).

\subsection{Phase space analysis}

The phase-space analysis by Hart (2003) is used to describe the cyclone structure and its evolution. This analysis involves three parameters: thermal symmetry $(B)$ of the cyclone and the lower and upper cyclone thermal wind $\left(\mathrm{T}_{L}\right.$ and $\mathrm{T}_{U}$ ). Below we briefly outline these three parameters. For a more detailed description we refer the reader to Hart (2003). The thermal symmetry $B$ is computed by the difference of the geopotential height averaged over two semicircles with a radius of $500 \mathrm{~km}$ around the cyclone center:
$B=h\left(\left.\overline{Z_{600 \mathrm{hPa}}-Z_{900 \mathrm{hPa}}}\right|_{R}-\left.\overline{Z_{600 \mathrm{hPa}}-Z_{900 \mathrm{hPa}}}\right|_{L}\right)$

where $h$ is an integer of value +1 for Northern Hemisphere, $Z$ the geopotential height and the subscripts $R$ and $L$ indicate the semicircles right and left of the propagation direction, respectively. Near-zero values of $B$ indicate a thermally symmetric or tropical character, while high values indicate a thermally asymmetric character, which is often extratropical. Generally, the threshold for determining whether the cyclone is symmetric or asymmetric is $10 \mathrm{~m}$ (Hart and Evans 2001; Hart 2003).

The lower and upper thermal wind $\left(\mathrm{T}_{L}\right.$ and $\left.\mathrm{T}_{U}\right)$ are computed for the 900-600 and 600-300 $\mathrm{hPa}$ layers respectively:

$T_{L} \equiv-\left|V_{T}^{L}\right|=\left.\frac{\partial(\Delta Z)}{\partial \ln p}\right|_{900 \mathrm{hPa}} ^{600 \mathrm{hPa}}$

$T_{U} \equiv-\left|V_{T}^{U}\right|=\left.\frac{\partial(\Delta Z)}{\partial \ln p}\right|_{600 \mathrm{hPa}} ^{300 \mathrm{hPa}}$

where $p$ is pressure and $\Delta Z=Z_{\max }-Z_{\text {min }}$, where $Z_{\max }$ and $Z_{\min }$ are the maximum and minimum geopotential height at a specific pressure level within the $500 \mathrm{~km}$ radius of the cyclone center. To get the average value of $\Delta Z$ over the specified pressure ranges, a linear regression of the $\Delta Z$ and $\ln p$ data is made with a vertical resolution in $p$ of $50 \mathrm{hPa}$. The angle of this linear regression is used as the derivative of $\Delta Z$ to $\ln p$. Positive (negative) values of $\mathrm{T}_{L}$ or $\mathrm{T}_{U}$ indicate cores that are warm (cold) compared to the environment. This is because the cyclone height perturbation $(\Delta Z)$ is proportional to the geostrophic wind (Hart 2003), and the derivative to $p$ then basically is an expression for a scaled thermal wind magnitude, which is positive (negative) for a warm (cold) core.

In addition to these three parameters the cyclone size is computed, which is defined by the mean distance of the gale force wind field edge $\left(16.9-18.5 \mathrm{~m} \mathrm{~s}^{-1}\right)$ towards the center of the cyclone.

\subsection{Baroclinic instability}

During the crossing of the North Atlantic, the cyclone structure and development is affected by baroclinic instability, which plays a major role during the extratropical transition (Hart and Evans 2001). The baroclinic growth rate in case of baroclinic instability is often expressed by the Eady index (Hoskins and Valdes 1990; Hart and Evans 2001):

$\sigma=0.31 \frac{f}{N}\left|\frac{\partial u}{\partial z}\right|$,

where $f$ is the Coriolis parameter, $u$ the zonal wind and $N^{2}=\frac{g}{\theta} \partial \theta / \partial z$ the Brunt-Väisälä frequency in which $\theta$ is the potential temperature and $g$ the gravitational constant. 
Using the thermal wind balance and changing to pressure coordinates, the Eady index can be rewritten as $\sigma=0.31 \frac{g}{N}\left|\frac{\nabla \theta}{\theta}\right|$, where now $N^{2}=-g^{2} \frac{\rho}{\theta} \partial \theta / \partial p$ (with $\rho$ the density). In regions where $N^{2} \leq 0$ there is convective instability.

The Eady index is a measure for the slope of the isentropes (surfaces of constant $\theta$ ). Vertical displacements in a dry atmosphere are only baroclinically unstable if the slope of their movement is smaller than the slope of the basic state. However, we study systems that include moisture. A consequence of the air being moist is that it reduces the stability, as the air may release latent heat through condensation in the ascending branch of developing baroclinic waves. Therefore, the relevant slopes for instability are those of the equivalent potential temperature $\left(\theta_{E}\right)$ which takes into account the change in temperature due to the release of latent heat. For moist systems, such as tropical cyclones, we argue that baroclinic growth rate is better represented by a moist Eady index $\sigma_{m}$ in which $\theta$ is replaced by $\theta_{E}$ :

$\sigma_{m}=0.31 \frac{g}{N_{e}}\left|\frac{\nabla \theta_{e}}{\theta_{e}}\right|$,

where $N_{e}$ is the Brunt-Väisälä frequency using the equivalent potential temperature $\theta_{e}=\theta \cdot e^{L_{v} r_{s} / c_{p} T} . L_{v}$ is the latent heat of evaporation, $r_{s}$ the saturation mixing ratio, $c_{p}$ the heat capacity of dry air and $T$ the absolute temperature, resulting in $N_{e}=\sqrt{-g^{2} \frac{\rho}{\theta_{e}} \frac{\partial \theta_{e}}{\partial p}}$. We will use the moist Eady index in Sect. 4.2.

\section{Classification of cyclone life cycles}

The cyclone tracking algorithm outlined in Sect. 2.2 on the MERRA data provides a set of 53 cyclones. Originating

Table 1 Characteristics of the four different life cycle classes, showing number of storms, average pressure minimum and average wind maximum (shown with standard deviations). The last column shows the latitude where they enter Europe (i.e. entering the rectangle with from latitudes equatorward of $37.5^{\circ} \mathrm{N}$, these cyclones encounter different physical circumstances when crossing the North Atlantic and undergo various kinds of structure evolution before reaching Europe. Using the phasespace analysis of Hart (2003), four physically distinct life cycle classes have been identified. These life cycle classes describe the different possible transitions a cyclone may undergo when entering the midlatitudes. In the classification we have been guided by the known structure evolutions that have been described in the literature (Hart 2003; Hart and Evans 2001; Jones et al. 2003; Maue 2010; Hart et al. 2006). The four classes are described below and summarized in Table 1. Do note that, due to the limited set of cyclones, some of the differences among the stated variables are statistically not significant.

\subsection{Symmetric warm-core development: tropical cyclone life cycle}

Cyclones with tropical characteristics can be characterized by a thermally symmetric or non-frontal structure ( $B$ $<10 \mathrm{~m})$ and a warm core $\left(\mathrm{T}_{L}>0, \mathrm{~T}_{U}>0\right)$. Cyclones of the tropical life cycle start with these characteristics. The lower-troposphere warm core increases upwards due to sustained convection (Hart 2003). Combined with subsidence within the eye, a warm core is established, visible at the start of Fig. 1a by a high $\mathrm{T}_{L}$ and a slightly positive $\mathrm{T}_{U}$ - They generally lose this warm-core structure when they encounter colder SSTs on their way to Europe. The fact that these cyclones do not develop thermal asymmetry ( $B$ remains $<10 \mathrm{~m}$, Fig. 2a) can be explained by the fact that they are not subject to strong vertical shear, trough interaction or baroclinicity. In the early phase of this life cycle, the cyclone's spatial extent in wind field is usually small $(200-400 \mathrm{~km})$, and steadily grows in time. The pressure minimum is in some cases found early in the life

lower left corner $15^{\circ} \mathrm{W}$ by $37.5^{\circ} \mathrm{N}$ ) and subsequent standard deviation. The warm seclusion life cycle has been subdivided into two classes (see Sect. 4.2)

\begin{tabular}{|c|c|c|c|c|c|}
\hline & Class & Amount & $\overline{p_{\min }}(\mathrm{hPa})$ & $\overline{v_{\max }}\left(\mathrm{m} \mathrm{s}^{-1}\right)$ & $\begin{array}{l}\text { Enter } \\
\text { Europe } \\
\left({ }^{\circ} \mathrm{N}\right)\end{array}$ \\
\hline a. & Tropical cyclone life cycle & $8(15 \%)$ & $977 \pm 9$ & $21.9 \pm 1.7$ & $52 \pm 4$ \\
\hline b. & Extratropical cyclone life cycle & $7(13 \%)$ & $970 \pm 13$ & $21.5 \pm 2.3$ & $58 \pm 4$ \\
\hline c. & Classic ETT* cyclone life cycle & $10(19 \%)$ & $972 \pm 7$ & $22.5 \pm 1.7$ & $55 \pm 7$ \\
\hline \multirow[t]{4}{*}{ d. } & Warm seclusion (WS) life cycle & $28(53 \%)$ & $963 \pm 13$ & $22.5 \pm 2.4$ & $53 \pm 8$ \\
\hline & Extratropical WS life cycle & $17(32 \%)$ & $967 \pm 14$ & $21.6 \pm 2.2$ & $51 \pm 7$ \\
\hline & Tropical WS life cycle & $11(21 \%)$ & $958 \pm 13$ & $23.9 \pm 2.1$ & $58 \pm 8$ \\
\hline & Total & $53(100 \%)$ & $968 \pm 13$ & $22.2 \pm 2.1$ & $54 \pm 7$ \\
\hline
\end{tabular}

*ETT is an abbreviation for extratropical transition 
cycle during tropical intensification, but in other cases it is found near the point where the cyclone, after attaining a deep cold-core structure that has been developed over cold SSTs, re-establishes a shallow warm core. The cold core development in this life cycle (Fig. 2a) is different from other literature (e.g. Hart 2003). We speculate that this caused by the fact that we only investigate cyclones with this life cycle that cross the North Atlantic and reach Europe, whereas in previous literature this category contained mostly cyclones confined to the tropics.
Fig. 1 Diagrams showing the thermal wind $\left(\mathrm{m}^{2} \mathrm{~s}^{2} \mathrm{~kg}^{-1}\right)$ at $900-600$ and $600-300 \mathrm{hPa}$ for different cyclone life cycle classes: tropical life cycle (a), extratropical life cycle (b), classic ETT life cycle (c), warm seclusion life cycle (d). Capitals $\mathrm{S}$ and $\mathrm{E}$ in the figures point to the beginning and end of the composition, which is by averaging the life cycles around the time of pressure minimum, with the minimum averaging of at least three cyclones. Colors indicate central mean sea level pressure and dot size indicates system size, based on mean radius of gale force winds (17 $\mathrm{m} \mathrm{s}^{-1}$ ). Grey shaded lines show all the single life cycles of that class. A 24 h running mean has been used for all graphs. Timestep in composite figures is $6 \mathrm{~h}$.

Fig. 2 As Figure 1 but with the thermal symmetry $B(\mathrm{~m})$ at the vertical axis. Dashed horizontal line shows the threshold value of $B=10 \mathrm{~m}$.
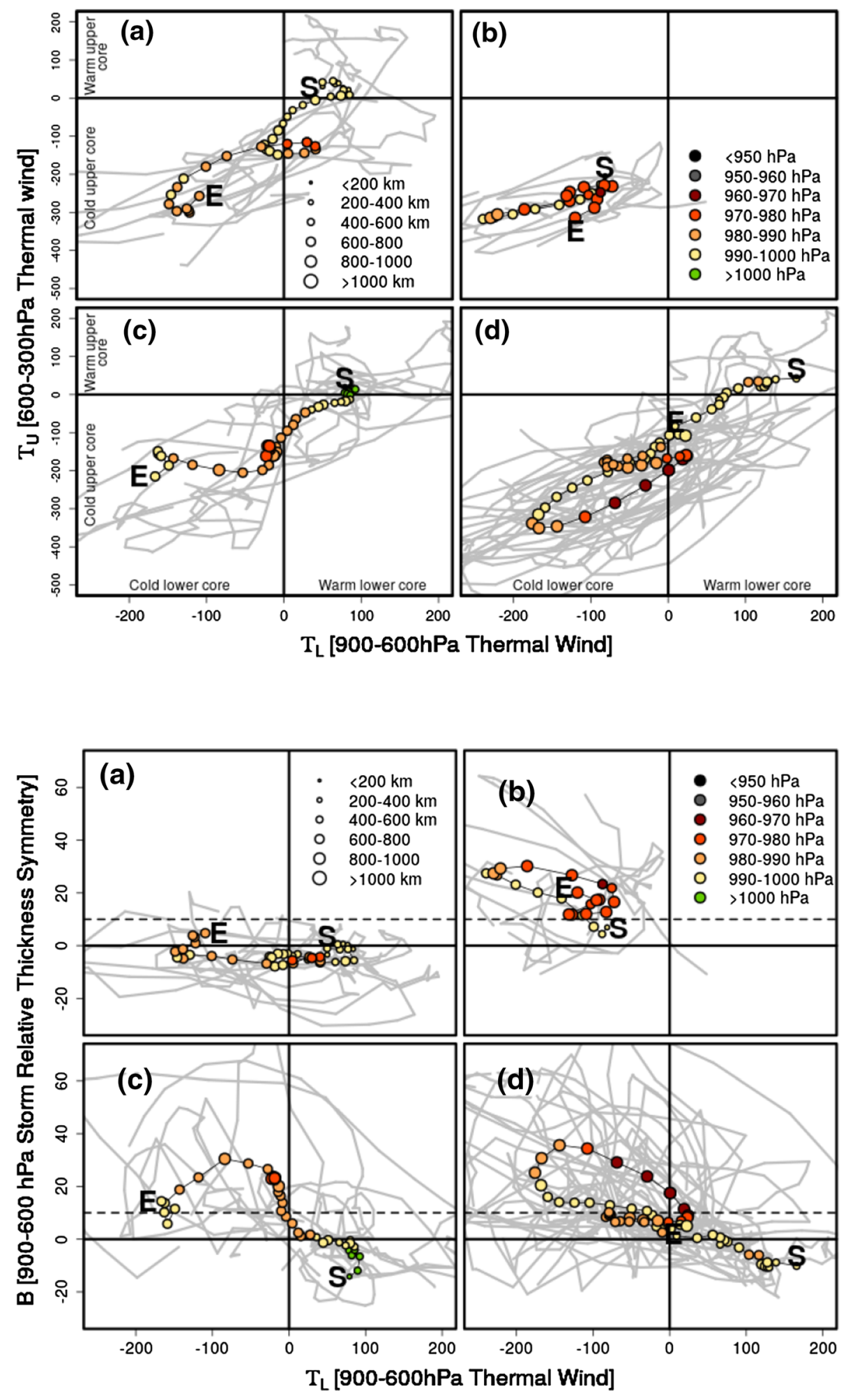
We find that about $15 \%$ of the observed cyclones follow this life cycle. These cyclones tend to enter Europe in France and Great Britain and never attain latitudes higher than $60^{\circ} \mathrm{N}$. The average wind speed maximum and average pressure minimum of this class are $21.9 \pm 1.7 \mathrm{~m} \mathrm{~s}^{-1}$ and $977 \pm 9 \mathrm{hPa}$, respectively, which makes this the weakest class of low-latitude originating storms entering Europe (see Table 1).

\subsection{Asymmetric cold-core development: extratropical cyclone life cycle}

The cyclones pertaining to the extra-tropical life cycle originate with a cold-core structure $\left(\mathrm{T}_{L}<0, \mathrm{~T}_{U}<0\right)$ (Fig. 1b) and retain it throughout their development in combination with a strong thermal asymmetry $(\mathrm{B}>10)$ (Fig 2b). Although coming from below $37.5 \mathrm{~N}$, these are the characteristics of an extratropical cyclone. Often visible in these cyclone life cycles is an increase of the cold-core structure in an early phase, which is reflected by $\mathrm{T}_{L}$ becoming increasingly negative. The middle- and upper-tropospheric height gradients above the surface cyclone then intensify (isobaric heights decrease) more rapidly than near the surface, leading to an increasing cold-core cyclone signature. With $B$ increasing, thermally direct circulation dictates that cold air is advected in the rear of the cyclone and warm air is advected further north, sustaining the strongly negative $\mathrm{T}_{L}$. This is often followed by an increase of $\mathrm{T}_{L}$ as can be seen in Figs. $1 b$ and $2 b$, where also an increase in pressure is clearly visible. For detailed analyses of this life cycle, see Hart (2003). Occlusion (following the Norwegian cyclone model) of the cyclone fronts can be recognized by re-establishing thermal symmetry in the latter phase of the cyclone life cycle. If the cyclone does not interact with another trough or is not subject to increased surface fluxes, further intensification stops and the cyclone decays. The radius of the system (mean gale force wind radius) is relatively large throughout the extratropical cyclone life cycle (Fig. 1b).

About $13 \%$ of analyzed cyclones follow an extratropical life cycle. These cyclones tend to penetrate further north than cyclones with a tropical life cycle, reaching Europe at the northernmost point of Great Britain or even near Iceland. The average wind speed maximum and average pressure minimum of this class are $21.5 \pm 2.3 \mathrm{~m} \mathrm{~s}^{-1}$ and $970 \pm 13 \mathrm{hPa}$, respectively, which makes these storms of moderate strength among the low-latitude originating storms entering Europe (see Table 1).

\subsection{Extratropical transition: classic ETT cyclone life cycle}

The first two classes mentioned above (tropical and extratropical cyclone life cycles) are called conventional or single phase life cycles as they do not undergo major phase transitions in thermal symmetry and thermal wind (Hart 2003). The remaining two classes do undergo major phase transitions and differ in the experienced forcing mechanisms throughout their life cycle.

One of these major phase transitions is extratropical transition (ETT), changing the warm-core symmetric structure of a tropical cyclone into the cold-core asymmetric structure of an extratropical cyclone (Jones et al. 2003). The tropical origin is visible in Fig. 2c, with near-zero or even negative values of $B$ and positive values of $\mathrm{T}_{L}$. This is called the tropical stage. One would expect to find positive values of $\mathrm{T}_{U}$, too, which is on average not the case (Fig. 1c). This depends on the maturity of the tropical cyclone. Some do start with a positive $\mathrm{T}_{U}$, while others do not as can be seen from the individual life cycles in Fig. 1c. In this tropical stage, the cyclone radius is relatively small but slowly increasing, similar to the early phase of the tropical (conventional) life cycle. We adopt the criterion Hart (2003) proposed for the onset time of the ETT, when $B$ exceeds 10 $\mathrm{m}$, which corresponds to the cyclone entering a baroclinic environment (Hart 2003; Klein et al. 2000).

After the ETT, in the second transformation or hybrid stage, the cyclone interacts with its new environment, which usually consists of merging with an extratropical system or upper-level trough. During this stage, the tropical cyclone generally develops an increased translation speed. In the early stages of ETT, the cyclone tends to weaken first (Hart and Evans 2001), which could be attributed to the interaction between the cyclone and an upper-level trough, as this is associated with high vertical wind shear. The decrease in intensity of the cyclone also depends on the inner-core convection evolution by the environmental changes (Jones et al. 2003). Important changes after an ETT are the loss of organized convection in the inner core, the increase in translation speed, the loss of upper-level outflow circulation, increased frontogenesis, cyclone vertical tilt, asymmetry in the precipitation, moisture and temperature fields and the expansion of the gale force winds area (Hart and Evans 2001). Throughout the ETT, some cyclones directly attain a lower cold core and a thermally asymmetric structure (B $>10 \mathrm{~m}$; Fig 2c). However, ETT as it is described in Hart (2003), implies first a transition to the upper-right quadrant in Fig. 2c. The individual cyclone life cycles depicted in grey reveal that indeed many of them undergo this transition. This quadrant refers to the so-called hybrid stage, where a lower warm core $\left(\mathrm{T}_{L}>0\right)$ pertains in a baroclinic environment $(\mathrm{B}>10 \mathrm{~m})$. The latent heat release possible in the warm-core structure of the cyclone during this phase, may contribute to a deepening. The end time of the hybrid stage ( $T_{L}$ becomes negative) is sometimes referred to as the end of the ETT (Hart and Evans 2001). The duration of the hybrid stage differs among cyclones. The extratropical 
stage contains the decay and sometimes a reintensification of the cyclone. Both weak and strong cyclones can reintensify, but weak cyclones need to have a smaller duration of the hybrid stage for them to survive longer. The pressure evolution is therefore determined by weakening in an early phase of the ETT, the intensification during the hybrid stage (of cyclones that have one), and possible reintensification after the ETT (see Fig. 2c). Cyclones of this life cycle fade as cold-core, thermally asymmetric cyclones.

About 19\% of the observed cyclones follow this life cycle. The tracks of these cyclones start relatively deep in the tropics. They usually arrive in Europe around Great Britain. The average wind speed maximum and average pressure minimum of cyclones of this class are $22.5 \pm 1.7$ $\mathrm{m} \mathrm{s}^{-1}$ and $972 \pm 7 \mathrm{hPa}$, respectively, which is relatively weak (Table 1).

\subsection{Transition to warm seclusion: warm seclusion life cycle}

Finally, more than $50 \%$ of the storms undergo another major transition and become what is known as a warm seclusion storm. A warm seclusion occurs, when during the bending of the cold and warm front, part of the cold front gets separated from the cyclone center and propagates eastwards, perpendicular to the warm front (Shapiro and Keyser 1990). This process is called a frontal T-bone fracture. This is associated with trapping of warm air (the so-called bent-back warm front) in the core of the cyclone. A large part of the analyzed cyclones that attain a warm seclusion structure start with a warm $\mathrm{T}_{L}$ and a symmetric structure as seen in Figs. 1d and 2d. In their path towards Europe they lose their warm core structure and become asymmetric. During this transition they weaken. What distinguishes this life cycle from the classic ETT life cycle is that after this transition, due to the seclusion, a warm core is re-established again. This is caused by the release of latent heat and advection within the warm conveyor belt. The warm seclusion is often accompanied by a rapid intensification because both baroclinic processes and latent heat release contribute to the development of the storm. The average deepening is about $30 \mathrm{hPa}$ in 2 days. The minimum pressure is attained when the warm seclusion is completed. Thereafter the cyclone tilt disappears and they lose their warm core before they fade away. This life cycle is in agreement with the analysis of Maue (2010). It is interesting to note that sting jets are mainly found in this type of cyclones (Browning, 2004). This structure development is dominant for the storms that reach Europe. Moreover, the warm seclusion life cycle class contains the strongest storms that originate in the tropics. Eight out of the ten strongest storms are all warm seclusion storms. Also, on average they are the strongest storms with an average wind speed maximum of $22.5 \pm 2.4 \mathrm{~m} \mathrm{~s}^{-1}$ and average pressure minimum of $963 \pm 14 \mathrm{hPa}$.

\subsection{Summary}

We have divided the cyclones that reach Europe and originate from lower latitudes in four different classes based on the characteristic pathways in the Hart diagrams. Each of these classes describes a physically different life cycle. The life cycles of the individual cyclones shown in Figs. 1 and 2, support this classification. The four possible life cycles are schematically represented in Fig. 3, and correspond to the physical processes and transitions that cyclones may experience when they enter the midlatitudes with colder SSTs. This schematic picture aligns with previous studies (Hart 2003; Hart et al. 2006).

The minority of the cyclones experience small structure transitions (tropical and extratropical life cycle, 28\% in total), but the majority (72\%) undergoes major transitions in cyclone structure like extratropical transition and warm seclusion. Intensification of these cyclones mainly appears in the form of a reintensification at midlatitudes while warm seclusion intensification generates the lowest pressure values.

\section{Comparison of life cycles in terms of structure and development}

This section further investigates the structure and development of the four different classes. Because the warm

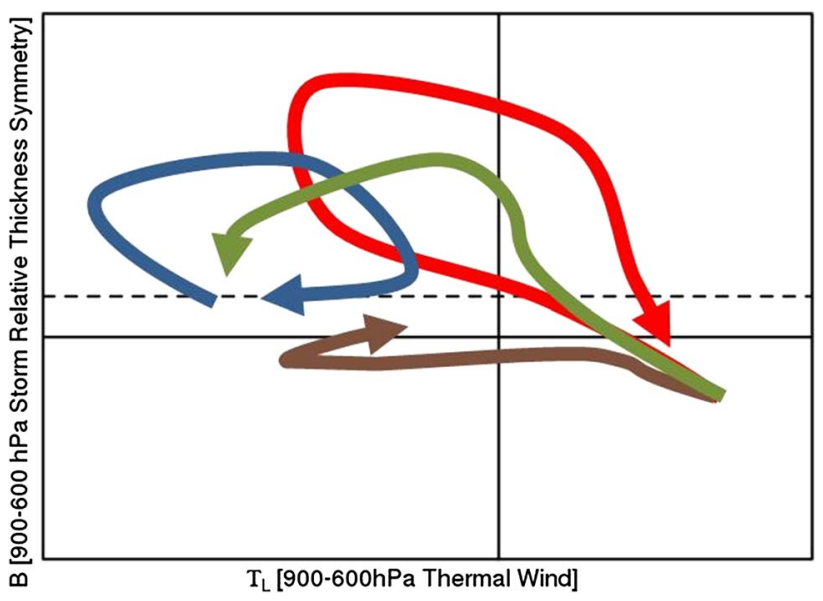

Fig. 3 Schematic picture showing the different cyclone stages within the cyclone life cycles. The blue line represents the extratropical life cycle, brown the tropical life cycle, green the extratropical transition life cycle and red the warm seclusion life cycle. Dashed line represents the threshold value of $B=10 \mathrm{~m}$. 
seclusion storms are the largest and strongest of the four classes that reach Europe, thereby being a potential risk for society, we will focus on the differences of these storms with respect to the other classes. The relative importance of warm seclusion storms is also motivated by the study of Baatsen et al. (2015), which suggests that those storms will increase in frequency and strength in a future warmer climate, arriving in Europe possibly with hurricane force wind.

This section will first elaborate on the cyclone structure, followed by an analysis of the development of $\theta_{E}$ at 850 $\mathrm{hPa}$, sea level pressure and the Eady growth parameter $\sigma_{m}$ at $500 \mathrm{hPa}$.

\subsection{Cyclone structure}

The cyclone structure is analyzed at the pressure minimum point in time because it is both a physical well-founded point in the life cycle to compare different cyclones and because the warm secluding process is usually just prior to the pressure minimum, which will allow for the warm seclusion features to be visible at this point. Figure 4 shows the trajectories of the warm seclusion cyclones together with the location of the minimum pressure. The figure bears large similarity with Fig. 5.6 of Maue (2010). It reveals that the minimum pressure is mostly attained during the later phase of their life cycle, and often within the European domain. The composite tracks of the different life cycles (lower right panel Fig. 4) reveal that the warm seclusion storms have longest tracks, starting in the deep tropics and penetrating far into Northern Europe. An elaboration of the distinction between two different warm seclusion life cycles made in this panel can be found in the next section.

Figure 5 shows the composite structures of the four cyclone life cycles at the time when central sea level pressure is at a minimum. A first observation is the overall lower $\theta_{E}$ in the warm seclusion panel with respect to that in the tropical life cycle and ETT panels, which is mainly because of the relatively late stage and more northward location at which these cyclones intensify. Comparing the $\theta_{E}$ structure of these cyclones further with that of other cyclone life cycles, the main characteristics are the consistency of the figure, the curled warm conveyor belt (WCB), the eastward progressing cold front and the vertically

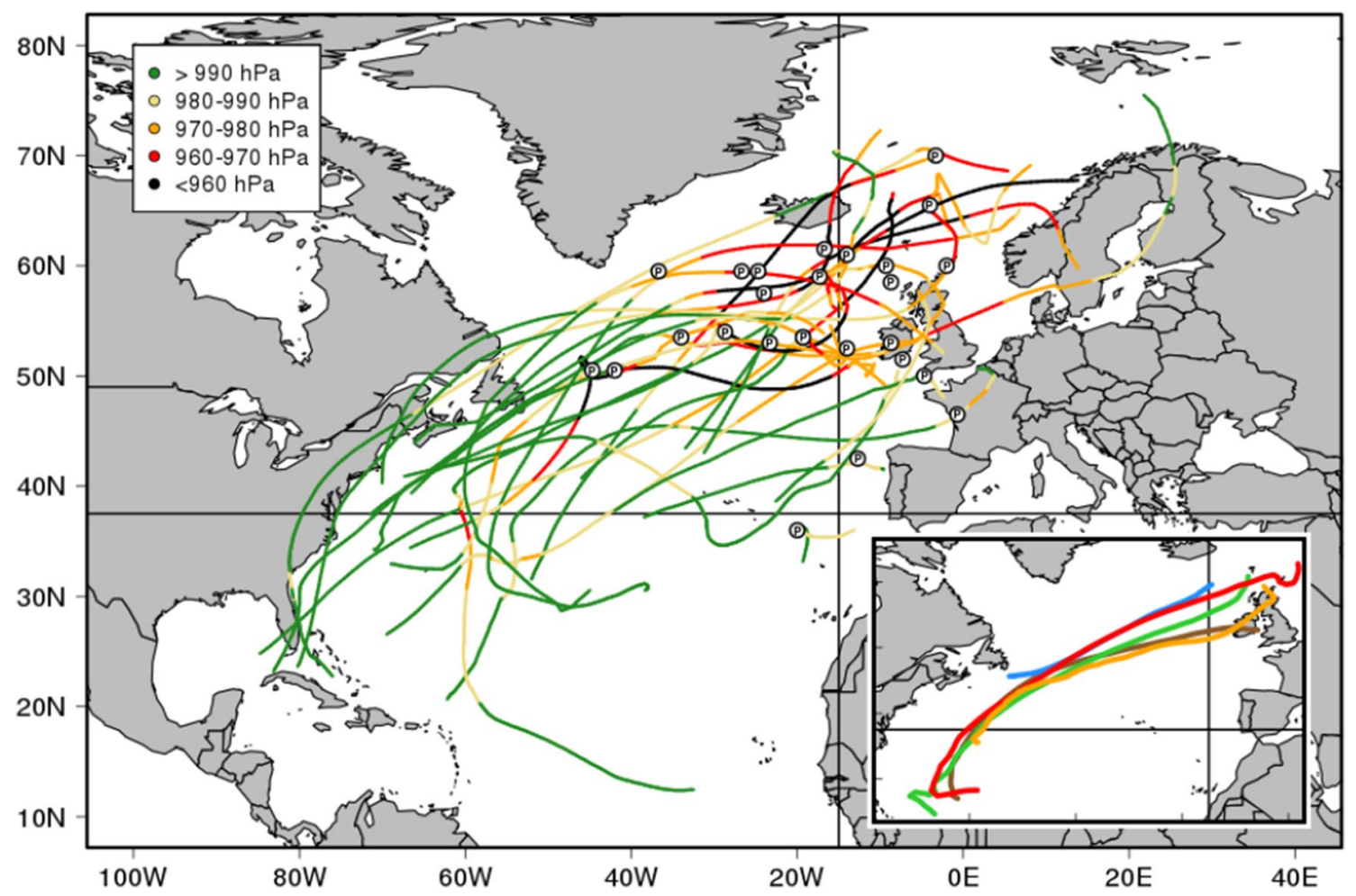

Fig. 4 Tracks of the warm seclusions. Large white dots marked with $P$ indicate the points of minimum pressure. Colors indicate pressure. Hourly data is shown, with a running mean of $24 \mathrm{~h}$. The frame on the lower right shows the composite ( $24 \mathrm{~h}$ running mean-) tracks of the different life cycles: tropical life cycle (brown), extratropical life cycle (blue), classic ETT life cycle (green), extratropical warm seclusion life cycle (orange) and tropical warm seclusion life cycle (red). The latter two are distinguished from the earlier discussed warm seclusion life cycle in Sect. 4.2. Averaging done around the point at which the tracks enter Europe with a minimum amount of three cyclones. Notable is that the average extratropical life cycle (blue in lower right panel) does not cross $37.5^{\circ} \mathrm{N}$, which is due to the high track variability in the individual tracks. 
stacked wind pattern, indicated here by the colocation of the maximum windspeed at $10 \mathrm{~m}, 850 \mathrm{hPa}$ and, to a lesser extent, $250 \mathrm{hPa}$. The smoothness of Fig. $5 \mathrm{~d}$ points to the consistency in the structure of warm seclusions at their highest intensity, which is not the case for the other life cycles. Additionally, the curled WCB displaying a welldefined comma shape is also quite unique to the warm seclusion life cycle. The eastward progressing cold front in Fig. $5 \mathrm{~d}$ is stronger than in any other cyclone life cycle pressure minimum. In analogy with the curled WCB, the cold front progresses far east, which is characteristic for the T-bone fracture. The intensity of the cyclone at this point in time, the far propagated low- $\theta_{E}$ region and vertically homogeneous eastward winds south of the cyclone may point to the presence of a dry intrusion, which favors the occurrence of a sting jet.

\subsection{Development of $\theta_{E}, p$ and $\sigma_{m}$}

The variables $\theta_{E}$, sea level pressure and the moist Eady growth rate $\sigma_{m}$ at the cyclone core provide information about the development of the cyclone and the specific phases the cyclone is in. High values of $\theta_{E}$ allow for stronger latent heat driven deepening as occurs in tropical cyclones, while $\sigma_{m}$ is a measure of baroclinic instability, which is the major energy source for extratropical cyclones.

More than half of the warm seclusion storms, although originating south of $37.5^{\circ} \mathrm{N}$, do not start with a tropical structure that is characterized by a warm core and a nonfrontal structure, but already possess extratropical characteristics. Although they are almost indistinguishable in their final warm seclusion structure, the different origin has implications for their ultimate pressure minimum and the development of $\theta_{E}$ and $\sigma_{m}$. We therefore divided the warm seclusion life cycle in two sub-cycles: warm seclusions that originated as tropical cyclones, i.e. following ETT, called tropical warm seclusions, and warm seclusions that originated as extratropical cyclones, i.e. without ETT, called extratropical warm seclusions.

Figure 6a shows the $\theta_{E}$ development of the cyclone life cycles. Cyclones that originated as tropical cyclones start with higher values of $\theta_{E}$ than their extratropical
Fig. 5 Composites of equivalent potential temperature (shaded in $\mathrm{K}$ ) at $850 \mathrm{hPa}$ in horizontal cross-sections of cyclone cores during the time when the central sea level pressure is at its minimum. The four panels show the different life cycles: tropical life cycle (a), extratropical life cycle (b), ETT life cycle (c) and the warm seclusion life cycle $(\mathbf{d})$. Thick contour lines show wind speed: $14 \mathrm{~m} \mathrm{~s}^{-1}$ at $10 \mathrm{~m}$ (black), $25 \mathrm{~m}$ $\mathrm{s}^{-1}$ at $850 \mathrm{hPa}$ (white) and 30 $\mathrm{m} \mathrm{s}^{-1}$ at $250 \mathrm{hPa}$ (gray). Thin contour lines show contours of $0.5 \mathrm{~m} \mathrm{~s}^{-1}$ at $10 \mathrm{~m}$ (black) and 2 $\mathrm{m} \mathrm{s}^{-1}$ at 850 and $250 \mathrm{hPa}$ (white and gray). Horizontal and vertical axes show distance w.r.t. the cyclone center in $\mathrm{km}$.
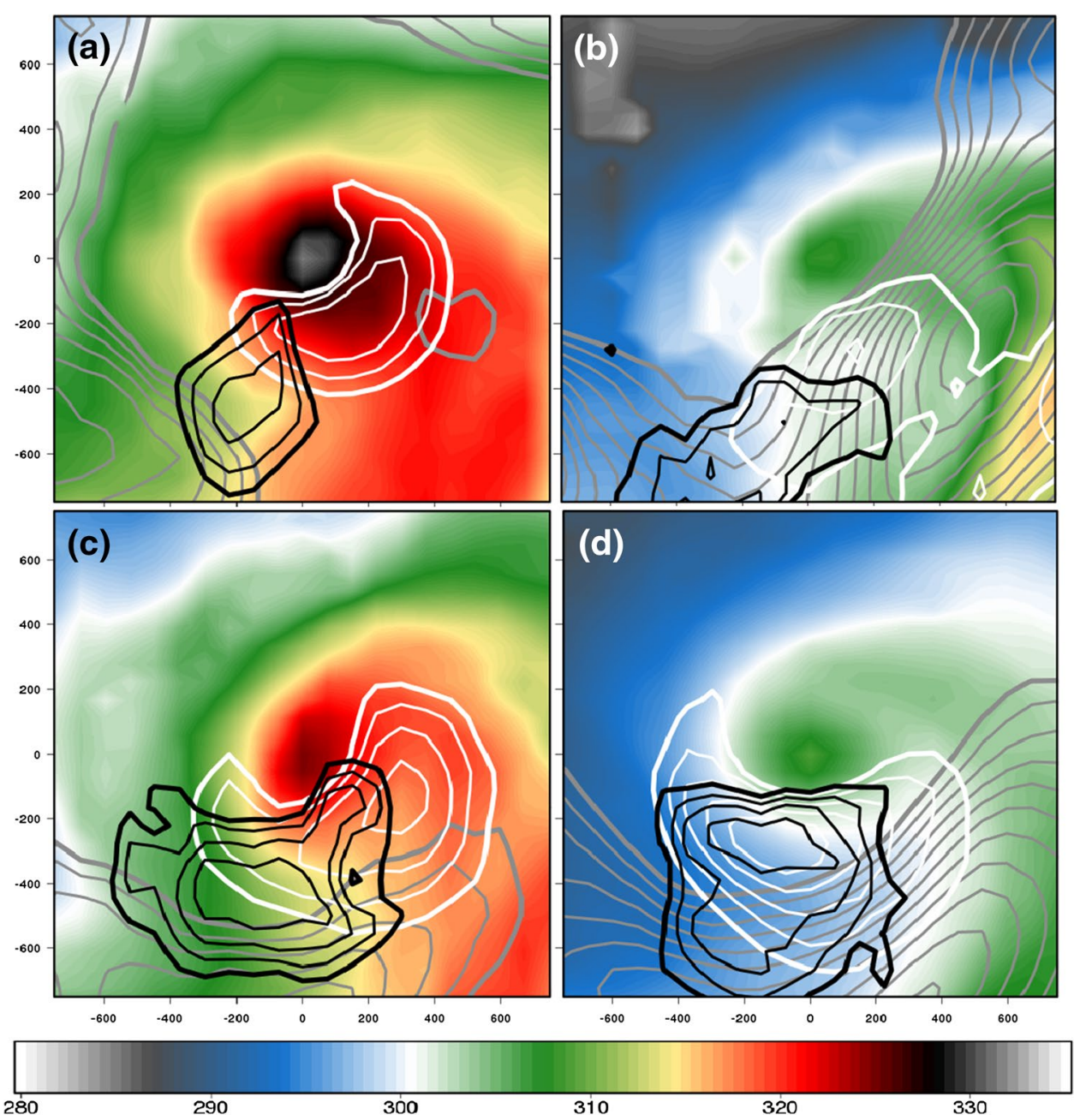
originating counterparts. The tropical warm seclusions lose rather much of their $\theta_{E}$ when they enter Europe. However, together with the extratropical warm seclusions they survive longest in Europe, up to more than 5 days. The large reduction of $\theta_{E}$ of the tropical warm seclusions could be explained by the fact that they travel relatively far northwards.

The sea level pressure development for each cyclone life cycle is shown in Fig. 6b. It reveals that both warm seclusion life cycles have their pressure minimum latest of all, about a day after entering Europe, while other cyclone life cycles have this minimum close to the time they enter Europe. Striking is the strong deepening rate of the warm seclusions, both starting a day prior to entering Europe. The tropical warm seclusion storms attain the lowest pressure with an average value of about $960 \mathrm{hPa}$. Notable are the long time periods of the tropical warm seclusion, extratropical transition and tropical life cycles before entering the midlatitudes (indicated by small vertical colored bars) in contrast to the extratropical and extratropical warm seclusion life cycles. This confirms the rather different origin of air mass type these cyclones have, although they all come from latitudes lower than $37.5^{\circ} \mathrm{N}$. In Fig. 6b, d, for the tropical warm seclusions, a slight minimum in pressure and maximum in wind speed can be distinguished roughly 6 days prior to entering Europe. This may refer to the tropical intensification of these cyclones prior to entering midlatitudes, but the signal is diffused due to the averaging of the individual evolutions. The midlatitude intensification and the loss of $\theta_{E}$ in tropical warm seclusions occur roughly at the same time, perhaps both influenced by ETT, which increases cyclone speed and therefore the rate at which its environment becomes colder. This may also enhance the intensification.

Figure 6c shows the moist Eady growth parameter $\sigma_{m}$. Being a measure of baroclinic instability, an increase of it after the entering of midlatitudes is expected. Remarkable is the increase in $\sigma_{m}$ of the tropical warm seclusions around their arrival in Europe, reaching the highest values during their lowest core sea level pressure. This indicates that moist baroclinic instability increases during ETT and the forming of the warm seclusion for this cyclone life cycle. A similar behavior is observed for the extratropical warm seclusions. Having these maxima in $\sigma_{m}$ near their moments of highest intensity, makes the warm seclusions rather unique with respect to other cyclone life cycles, which do not have such maxima. It points toward the important role of moist baroclinic instability for the warm seclusions during their reintensification and being responsible for their relative strength.

\section{Summary and conclusions}

Using the MERRA reanalysis for the period 1979-2013 we have analyzed the characteristics of 53 cyclones originating from the tropics that reach Europe. These characteristics have been classified into four classes based on
Fig. 6 Development of $\theta_{E}$ at $850 \mathrm{hPa}(\mathbf{a})$, sea level pressure (b), the moist Eady growth rate $\sigma_{m}$ at $500 \mathrm{hPa}(\mathbf{c})$ and $10 \mathrm{~m}$ wind speed (d) at the cyclone center for every life cycle class. Averaging done around the minimum central sea level pressure along the cyclone track, with a $12 \mathrm{~h}$ running mean. The grey bar shows the moment at which these storms (in average) arrive in Europe, and the small vertical colored bars show the moment at which cyclones from that particular class in average cross the $37.5^{\circ}$ latitude. Averages of at least three cyclones are shown. The colors are analogous to the lower right frame in Fig. 4.
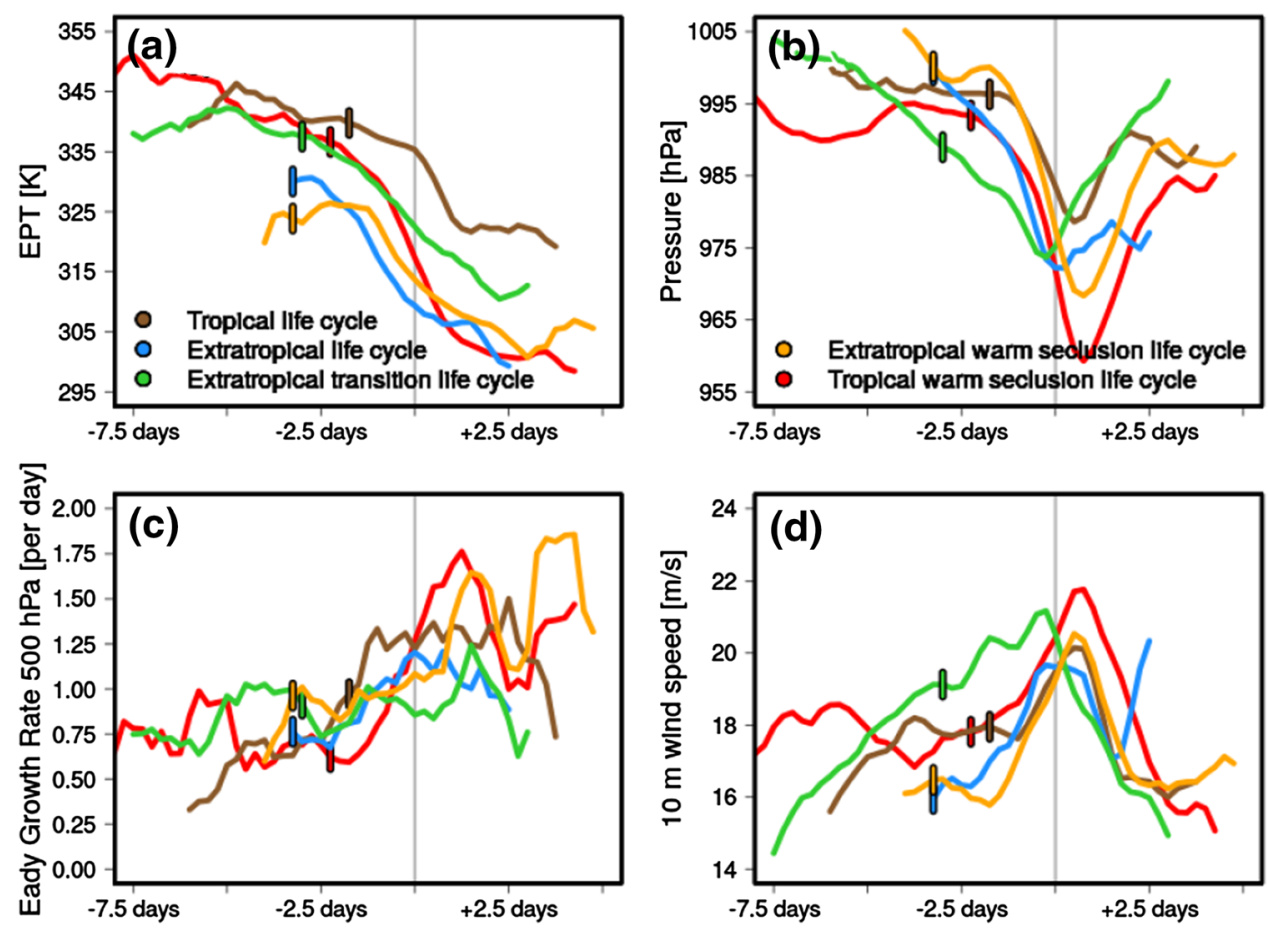

Time relative to reaching Europe 
the pathways in the phase space diagrams of Hart (2003). The classes describe the transitions cyclones undergo and the characteristic phases such as tropical, extratropical or hybrid they experience. These life cycles vary in trajectory and intensity. Of those four classes, warm seclusions (53\% of the cyclones) obtain the highest intensity in pressure and wind speed. At the time of their minimum sea level pressure, warm seclusions reveal a consistent structure consisting of a far eastward moving cold front, a northwestward curling WCB and the effects of dry intrusion. These features are almost non-existent in the other cyclone life-cycle types investigated in this study. Of the warm seclusions the subclass of tropical warm seclusion storms attain the lowest pressure and show the fastest re-deepening rates. Both baroclinic instability and release of latent heat contribute to the strong reintensification of these storms. The pressure minima of warm seclusions occur relatively late compared to other cyclone life cycles, about a day after entering Europe adding to the potential threat for Europe of these systems. However, in addition we note that all cyclone life cycles have their wind maximum after entering Europe (except for the ETT type). This study confirms the analysis of Hart et al. (2006) with respect to the warm seclusion cyclones and their enhanced risk.

Concerning the question whether storms with a tropical origin will pose an increased risk for Western Europe in a warmer climate, this study demonstrates that tropical warm seclusion storms are presently the strongest. In agreement with our results, Baatsen et al. (2015) show in a model study that tropical warm seclusion storms are the strongest tropical storms that reach Europe. The structural development of those storms described in that study reveals large similarity to life cycles we have seen in the MERRA reanalysis data. This supports the conjecture in Baatsen et al. (2015) that their intensity will increase in a warmer climate and warrants a more extensive study of their dynamics in observations as well with model simulations.

Acknowledgements This paper was partly funded through the PRIMAVERA project under Grant Agreement 641727 in the European Commission's Horizon 2020 research programme.

Open Access This article is distributed under the terms of the Creative Commons Attribution 4.0 International License (http:// creativecommons.org/licenses/by/4.0/), which permits unrestricted use, distribution, and reproduction in any medium, provided you give appropriate credit to the original author(s) and the source, provide a link to the Creative Commons license, and indicate if changes were made.

\section{References}

Agusti-Panareda A, Thorncroft C, Craig G, Gray S (2004) The extratropical transition of hurricane Irene (1999): a potential-vorticity perspective. Q J R Meteorol Soc 130:1047-1074

Baatsen M, Haarsma R, van Delden A, de Vries H (2015) Severe autumn storms in future Western Europe with a warmer Atlantic Ocean. Clim Dyn 45:949-964. doi:10.1007/s00382-014-2329-8

Browning KA (2004) The sting at the end of the tail: damaging winds associated with extratropical cyclones. Q J Meteorol Soc 130:375-399

Dorland C, Tol RSJ, Palutikof P (1999) Vulnerability of the Netherlands and northwest Europe to storm damage under climate change. Clim Change 43:513-535

Haarsma R, Hazeleger W, Severijns C, de Vries H, Sterl A, Bintanja R, Oldenborgh G, Brink H (2013) More hurricanes to hit Western Europe due to global warming. Geophys Res Lett 40:1-6

Hart R (2003) A cyclone phase space derived from thermal wind and thermal asymmetry. Mon Weather Rev 131:585-616

Hart R, Evans J (2001) A climatology of the extratropical transition of Atlantic tropical cyclones. J Clim 14:546-564

Hart RE, Evans JL, Evans C (2006) Synoptic composites of the extratropical transition life cycle of North Atlantic tropical cyclones: factors determining posttransition evolution. Mon Weather Rev 134(2):553-578

Hodges KI (1994) A general method for tracking analysis and its application to meteorological data. Mon Weather Rev 122(11):2573-2586

Hoskins, Valdes (1990) On the existence of storm tracks. J Atmos Sci 47:1854-1864

Jones SC, Harr PA, Abraham J, Bosart LF, Bowyer PJ, Evans JL, Hanley DE, Hanstrum BN, Hart RE, Lalaurette F, Sinclair MR, Smith RK, Thorncroft C (2003) The extratropical transition of tropical cyclones: forecast challenges, current understanding, and future directions. Weather Forecast 18:1052-1092

Klein P, Harr P, Elsberry R (2000) Extratropical transition of Western North Pacific tropical cyclones: an overview and conceptual model of the transformation stage. Weather Forecast 15(4):373-395

Maue RN (2010) Warm seclusion extratropical cyclones. Florida State University, Tallahassee

Murakami H, Wang Y, Yoshimura H, Mizuta R, Sugi M, Shindo E, Adachi Y, Yukimoto S, Hosaka M, Kusumoki S, Ose T, Kitoh A (2012) Future changes in tropical cyclone activity projected by the new high-resolution MRI-AGCM. J Clim 25:3237-3260

Schenkel BA, Hart RE (2012) An examination of tropical cyclone position, intensity, and intensity life cycle within atmospheric reanalysis datasets. J Clim 25(10):3453-3475

Shapiro MA, Keyser D (1990) Fronts, jet streams and the tropopause. Newton CW, Holopainen EO In: Extratropical cyclones, the Erik Palmeén Memorial Volume. Am. Meteorol. Soc., 1(3):167-191

Zhao M, Held I (2012) TC-Permitting GCM simulations of hurricane frequency response to sea surface temperature anomalies projected for the late-twenty-first century. J Clim 25:2995-3009 